\title{
AKT Family Gene Mutation
}

National Cancer Institute

\section{Source}

National Cancer Institute. AKT Family Gene Mutation. NCI Thesaurus. Code C96865.

A molecular genetic abnormality indicating the presence of mutations in the AKT family of genes. This family includes the AKT 1, AKT 2, and AKT 3 genes that are located on chromosomes 14, 19, and 1, respectively. 